\title{
EFFECT OF NANO HYDROXYAPATITE BONE GRAFT ON IMMEDIATE IM- PLANT PLACEMENT IN THIN RIDGE OF ANTERIOR ASTHETIC REGION
}

\author{
Ahmed M.A. Hommos*; Abd Elmoneam A. Abd Elghaffar*; Wael A. ElMohandes ${ }^{* * * *}$ and Yasser N. Helmy ${ }^{* * * *}$
}

\begin{abstract}
The loss of bone following tooth extraction is a significant clinical problem in implant dentistry as well as conventional restorative dentistry. The presence of a thin ridge presents a clinical challenge for proper positioning of endosseous dental implants. In the esthetic zone, bone loss can severely impact the appearance of implant restorations due to subsequent loss of interdental papillae, soft tissue recession, or loss of soft tissue volume which is essential in providing camouflage of abutments and restorative components. When the bone width is compromised, augmentation becomes necessary to increase the bone volume as this will enable placement of an implant as a fixed prosthesis. Nano hydroxyapatite bone graft material provides as a good synthetic material for ridge augmentation with minimal post-operative complication. Ridge splitting technique with simultaneous immediate implant placement is a minimally invasive technique for horizontal augmentation of maxillary narrow alveolar ridges. The introduction of cone-beam computed tomography (CBCT) for the maxillofacial region provides opportunities for dental practitioners to request multiplanar imaging. CBCT is an effective technical tool measurement to measure accurately the horizontal and vertical dimensions of the ridge. All patients was followed up clinically and radiogarphically using $\mathrm{CBCT}$ at intervals of 1,6 and 12 months.
\end{abstract}

KEY WORDS: Nano hydroxyapatite, Immediate implant, Ridge splitting, Bone graft, CBCT

\section{INTRODUCTION}

The loss of bone following tooth extraction is a significant clinical problem in implant dentistry as well as conventional restorative dentistry. The presence of a thin ridge presents a clinical challenge for proper positioning of endosseous dental implants. When the bone width is compromised, augmentation becomes necessary to increase the bone volume as this will enable placement of an implant as a fixed prosthesis ${ }^{(1)}$.

The etiology of alveolar ridge resorption or atrophy mostly depends on several factors as anatomical, pathological, functional or prosthetic factors that frequently compromises dental implant placement in a prosthetically ideal position. Therefore, the alveolar ridge splitting or expansion is considered as an optimal treatment. Also, augmentation of an insufficient bone volume is often indicated prior to or in conjunction with implant placement to attain predictable long-term functioning and an esthetic treatment outcome ${ }^{(2)}$. When the labio-palatal bone width is $3 \mathrm{~mm}$ or greater but less than $6 \mathrm{~mm}$, to allow implant placement, augmentation of the alveolar bone using a ridge expansion technique is a viable option. The $3 \mathrm{~mm}$ bone should have at least $1 \mathrm{~mm}$ of trabecular bone sandwiched between the cortical plates ${ }^{(2,3)}$. That will ensure $1.5 \mathrm{~mm}$ of bone

\footnotetext{
*Specialized Dental Hospital, Military Kobry EL Koba Complex.

**Professor, Oral and Maxillofacial Surgery Department, Faculty of Oral and Dental Medicine.Al-Azhar University (Boys-Cairo).

***Professor, Oral and Maxillofacial Surgery Department, Faculty of Oral and Dental Medicine.Al-Azhar University (Boys-Cairo).

****Assisstant Professor, Head of Oral and Maxillofacial Surgery Department of Specialized Dental Hospital, Military Kobry EL Koba Complex.
} 
(cortical and cancellous) on either side of the split ridge and allow the bone to spread and maintain a good blood supply, and this will allow immediate implant placement. There are significant advantages for using ridge expansion rather than onlay grafting. These advantages include simultaneous implant placement and grafting, lower possibility of cross infection from graft material and lower morbidity ${ }^{(4,5)}$.

Recently, an alternative surgical procedure, e.g. ridge split technique (RST) has been developed for reconstruction of the buccolingually reduced alveolar process. This procedure is composed of a lamellar cortical splitting of the alveolus ${ }^{(6,7)}$ after which the space is opened with osteotomes ${ }^{(8)}$, which generates room in the newly formed crest for implant placement. Chisels and hammers, as well as rotating burs or oscillating saws, have been demonstrated to cut bone very effectively. However, surgical complications such as soft tissue lacerations or thermal injury during the osteotomy have been reported with these techniques ${ }^{(9-11)}$.

Dental implants have become a predictable treatment option for restoring missing teeth. The purpose of tooth replacement with implants is to restore adequate function and esthetics without affecting adjacent hard and/or soft tissue structures ${ }^{(12)}$. it is critical to maintain the integrity of the peri-implant tissues since bone resorption takes place with or without implant placement in the fresh extraction site ${ }^{(13)}$. The influence of dental implant surface on primary stability has be analyzed. Results showed that the maximum torque to insert the implant depends on the friction coefficient between the implant surface and the placement wall, implant design, implant thread geometry and surface treatment ${ }^{(14)}$.

Autogenous bone grafts are still considered the gold standard in bone regeneration procedures. However, donor site morbidity, unpredictable resorption, limited quantities available, and the need to include additional surgical sites are drawbacks related to autograft that have intensified the search for suitable alternatives. Bone-substitute materials have increased in popularity as adjuncts to or replacements for autograft in bone augmentation procedures to overcome the limitations related to the use of autograft ${ }^{(11,12)}$.

No single biomaterial is optimum for every craniomaxillofacial application. Feynman's quest to create new technology and materials which are better and more efficient led to the introduction of 'Nanotechnology', a technology that deals with structures ranging in the size of 100 nanometers or smaller in at least one dimension and developing materials or devices within that size ${ }^{(15)}$. The basic idea of nanotechnology is to employ individual atoms and molecules to construct functional structures. Nanotechnology has revolutionized all fields from health care to engineering into a new archetype beyond traditional and dentistry is no exception. The speed at which progress has been made in science has introduced nanotechnology to dentistry from its theoretical basics instantly into the actual world. Nano dentistry is expected to make it possible to maintain near-perfect oral health through the use of nano materials, bioengineering and nano robotics ${ }^{(16,17)}$.

One of the major uses of cone beam computed tomography (CBCT) is presurgical implant planning. Linear measurement is used for the determination of the quantity of alveolar bone (height and width). Linear measurements are used in presurgical dental implant assessment. CBCT is highly accurate and reproducible in linear measurements in the axial and coronal image planes and in different areas of the maxillofacial region ${ }^{(18)}$.

\section{PATIENTS AND METHODS}

Thirty healthy patients with insufficient ridge width in edentulous anterior maxilla and in need for ridge splitting with immediate implant placement to facilitate rehabilitation of anterior missing teeth 
were randomly selected from the out-patient clinic of Sayed Galal University hospital and the specialized dental teaching hospital. The age of selected patients range from (20-40) years were devided into two groups.

Control group (group I) received ridge splitting technique and immediate dental implants without placement of nano hydroxyapatite bone graft, while the study group (group II) received ridge splitting and immediate implant placement with placement of nano hydroxyapatite (Nha) boone graft.

Patients with good general health condition without any systemic complications, good dental hygiene, anterior atrophic edentulous area of the maxilla and residual alveolar bone width range from 3-6 $\mathrm{mm}$ in estimated implant position were included in this study as inclusion criteria.

Exclusion criteria for patients' selection were those patients with poor oral hygiene or having diseases that may delay or prevent bone healing as lesions of oral cavity, bruxism, smoking, localized radiation therapy on the oral cavity, anti-tumor chemotherapy, as well as systemic diseases that compromise bone healing as liver, blood, kidney diseases or autoimmune diseases. Each patient signed a written consent having all details about the surgical procedure and the whole study schedule.

Preoperative evaluation includes the mesiodistal and labiolingual space of the implant insertion, as well as the intermaxillary space for occlusion and the gingival condition at the area of surgery. Radiographic examination was carried out with conventional radiographs as well as $\mathrm{CBCT}$ to review the bone density and the height of alveolar bone being in the area of implant placement and the anatomical structures in the area of surgery.

\section{Surgical procedure}

All patients rinsed for $1 \mathrm{~min}$ with chlorhexidine mouthwash $0.2 \%$ prior to the surgery (and twice a day for the following 2 weeks), and were treated un- der local anesthesia using Aarticaine hydrochloride 4\% with epinephrine 1: 100,000 (Septocaine, distributed by Septodont,Inc, USA, product of France). All surgeries were undertaken by the same surgeon and his surgical teams.

A conventional pyramidal mucoperiosteal flap extending from the mesial tooth to the distal tooth related to the surgical site was reflected to obtain access and visibility to the subperiosteal surgical site.

A sagittal osteotomy of the edentulous alveolar ridge was initiated at the center of the ridge until a mobile vestibular flap is obtained. The implant drillings with its various diameters was initiated under copious isotonic saline irrigation till reach to the final drill followed by implant insertion. A total of 30 Screw Plant Two-Stage Implant System (Spectra system, implant Direct, Legacy implant, (www.implantdirect.com) were placed immediately in the anterior maxillary area.

The space between the expanded bony plates and implants was packed with nano hydroxyapatite bone graft (Neo Active Apatite, GHIMAS S.p.A Via D. Cimarosa 8540033 Casalecchio di Reno (BO)). Nano hydroxyapatite bone graft is a bone augmentation material based on active hydroxyapatite. The hydroxyapatite (HA) is applied according to the manufacture. Tension-free flap was repositioned and sutured using resorbable suture material.

\section{Follow up:}

All patients was followed up clinically and radiogarphically using CBCT at intervals of 1, 6 and 12 months. Clinical evaluation was done to observe any pain, swelling, signs of infection, exposure of the implant or bone graft material or patient's body rejection for the implant or bone graft material. Radiographic assessment was done using CBCT to evaluate the bone density using the gray scale analysis, and to evaluate the bone volume of the alveolar ridge at intervals of 1, 6 and 12 months. 


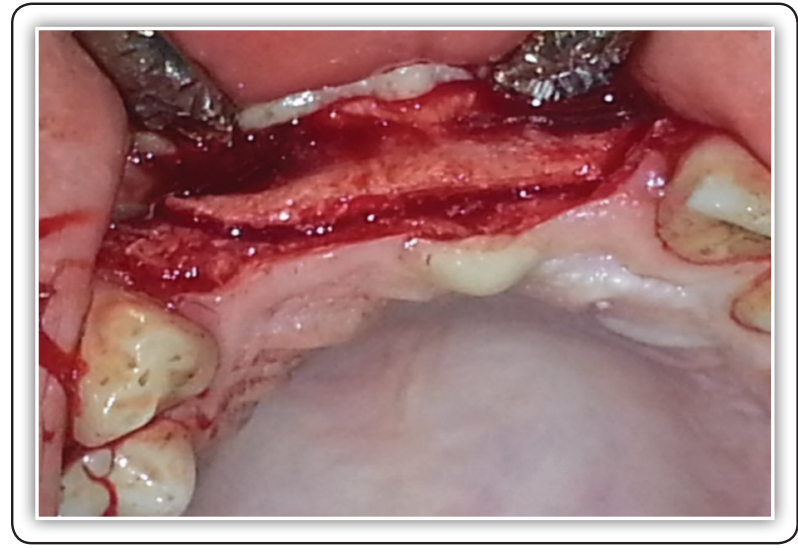

FIG (1) Complete formation of the horizontal and vertical osteotomy cut.

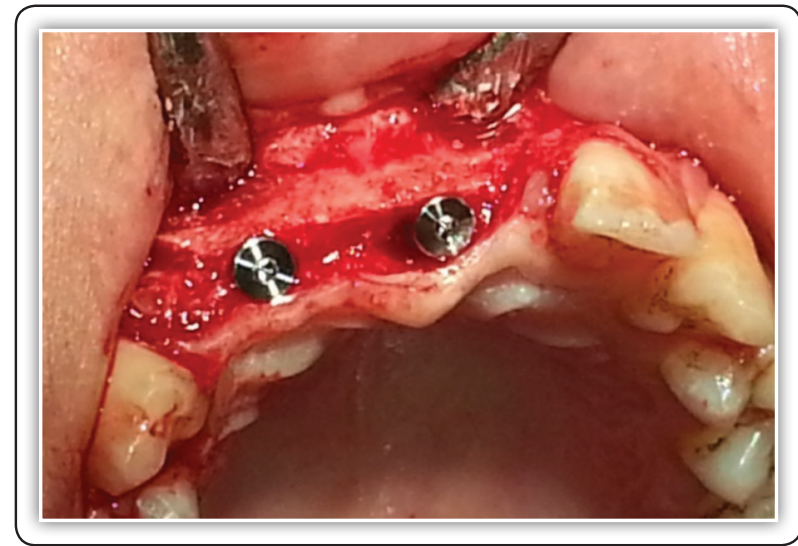

FIG (2) Implants completely seated in the pre-planned positions.

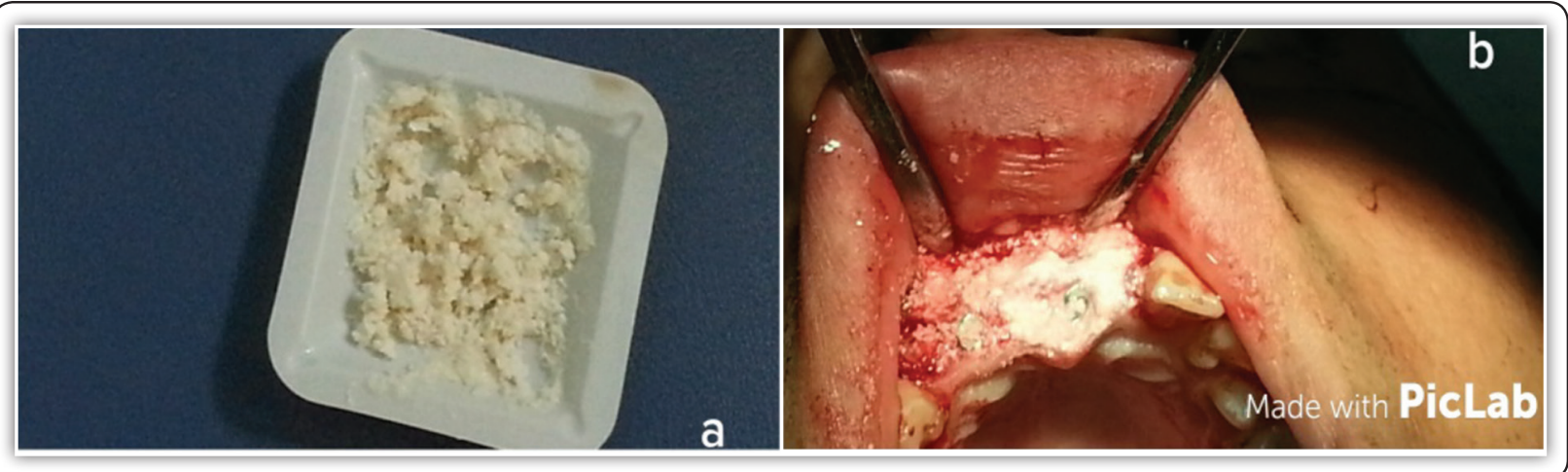

FIG (3) a: The Nano hyydroxyapatite bone graft after mixing it with saline. b: Bone grafting around Implants.
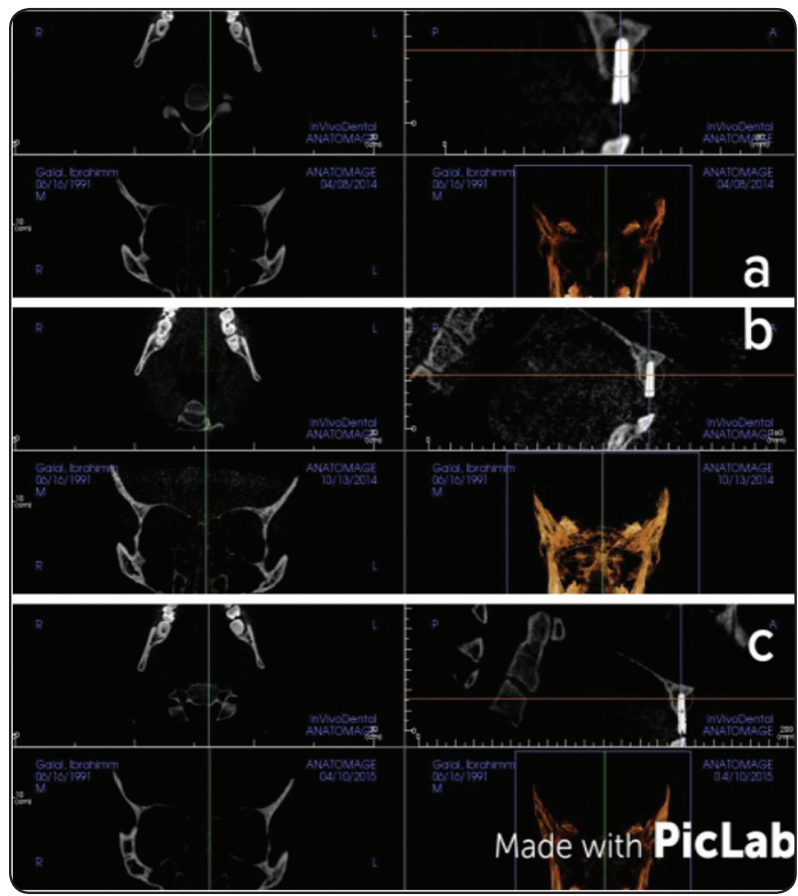

FIG (4) a: 1 month post-operative follow up. b: 6 month post-operative follow up. c: 12 month post-operative follow up.

\section{RESULTS}

By making initial comparison between the obtained data in both groups, we can predict that the decrease in bone height, depth, and density from 1 to 6 months is greater in group I than in group II, also, decrease in bone height and depth from 6 to 12 months is greater in group I than in group II, while, the increase in bone density from 6 to 12 months is greater in group II than in group I. The following statistical analysis will be done to confirm this prediction.

In group I (control group) the change that occurred during the first follow-up interval (from 1 to 6 months) was greater than that occurred during the second follow-up interval (from 6 to 12 months) for both bone height and depth. Bone density decreased from 1 to 6 months then increased again after 
12 months, also it was found that the change decrease in bone density that occurred from 1 to 6 months was greater than the change that occurred from 6 to 12 months, and this means that the decrease in bone density from 1 to 6 months was greater than the increase in bone density from 6 to 12 months. The statistical analysis using paired samples $\mathrm{T}$ test indicated that the difference in the changes that occurred during the two follow-up intervals was statistically significant for all evaluated parameters.

In group II (study group) the change that occurred during the first follow-up interval (from 1 to 6 months) was greater than that occurred during the second follow-up interval (from 6 to 12 months) for both bone height and depth. It was found that bone density decreased from 1 to 6 months then increased again after 12 months, the change (decrease in bone density) that occurred from 1 to 6 months was greater than the change (increase in bone density) that occurred from 6 to 12 months, this means that, the decrease in bone density from 1 to 6 months was greater than the increase in bone density from 6 to 12 months. The statistical analysis using paired samples $\mathrm{T}$ test indicated that the difference in the changes that occurred during the two follow-up intervals was statistically significant for all evaluated parameters.

The difference in bone height, depth, and density between the control and study groups from 1 to 6 months was evaluated as the decrease in bone height, depth, and density that occurred in group I (control group) was greater than that occurred in group II (study group) from 1 to 6 months. The difference in bone height, depth, and density between the two groups from 6 to 12 months was also evaluated as the decrease in bone height and depth, in group I (control group) was greater than that occurred in group II (study group) from 6 to 12 months, while the increase in bone densities as determined in table I and table II was greater in group II (study group) than in group I (control group) from 6 to 12 months.

\section{DISCUSSION}

Success and survival rates vary from $92-100 \%{ }^{(47)}$. In our study the scale rate was $10 \%$. There are many advantages to this procedure, one of them is that it requires only one surgical site as one surgical stage only, while the intra-oral or extra-oral harvesting bone requires a second surgical site, and thus reducing patient morbidity ${ }^{(45)}$.Implants placed immediately after the ridge split procedure also reduces patient costs and treatment time ${ }^{(19,20)}$.

In 2 cases in this investigation minor fracture of the buccal plate did occur. This may occur during all of the three fundamental surgical steps of the procedure as the ridge expansion using the bone chisels and/or osteotomes, implant site preparation using the twist drills or implant insertion. In previous studies, the risk of cortical plate fracture is minimal during implant placement ${ }^{(21,22)}$.

During the ridge expansion using the bone chisels and osteotomes, only the buccal cortical plate of the maxilla is displaced in a labial direction. The lingual/palatal cortical plates are stronger and are not weakened during the expansion. The cortices follow the path of least resistance which is towards the labial aspect ${ }^{(23,24)}$.

Placement of bone graft processed by nano technology as nano hydroxyapatite bone graft showed very good prognosis in this study through its great accessibility for bone formation rather than leaving the ridge splitting with immediate implant placement without placement of bone graft or any other type of bone graft with micro granules. Nano hydroxyapatite bone graft shows more benefits than micro hydroxyapatite in bone formation, better bioactivity as a bone implant and repair material ${ }^{(25)}$. The rigidity, toughness, dimensional stability, and biocompatibility of nHA are excellent. Its shape, structure, and composition are similar to those of apatite in human bone, and $\mathrm{nHA}$ is similar in size to natural inorganic minerals in bone, facilitating its identification by the cells and molecules in the human body. 
Also nHA has good osteoconduction properties, and its mechanical properties, especially compressive strength, flexural strength, and modulus of elasticity, are similar to those of human cortical bone. Therefore, nHA has better biological performance, and composite materials synthesized from nHA are becoming the first choice of replacement material for treatment of bone defects ${ }^{(26,27)}$.

The surgical procedure was well tolerated by most of the patients, as ten percent (6/60 implants) of the implants placed in this study exhibited significant peri-implant bone resorption6 months after the implant insertion. In one patient, a moderate fracture of the buccal plate occurred during implant placement. However, one patient who exhibited marginal bone loss around the implants healed uneventfully with no marginal bone resorption noted at the uncovery surgery or throughout the post-operative visits. Several studies reported early marginal peri-implant bone loss after placing implants with simultaneous ridge splitting ${ }^{(21)}$.

\section{REFERENCES}

1. C, Misch. Contemporary Implant Dentistry. St. Louis, MO: Mosby Elsevier Publishing Co. 2008.

2. Gupta A, Tiwari B, Goal H, Shekhawat H. Residual Ridge Resorption. A review. 2010, Vol. 2, pp. 7-10.

3. Duncan J and Westwood M. ; : Ridge widening for the thin maxilla.A clinical report. 1997, Vol. 12, pp. 224-227.

4. Elian N, Jalbout Z, Ehrlich B, Classi A,Cho Sang-Choon, Kahtani Fahaed-Al, Froum S, Tarnow D.A. two stage full arch ridge expansion technique. Review of the literature and clinical guidelines. 2008, Vol. 17, pp. 16-20.

5. Guirado J, Yuguero M, Carrion del Valle M. A maxillary ridge splitting technique followed by immediate placement of implants: a case report. 2005, Vol. 14, pp. 14-20.

6. Koo S, Dibart S, Weber H. Ridge splitting technique with simultaneous implant placement. Compendium Contin Educ Dent. 2008, Vol. 29, pp. 106-110.

7. Coatoam GW and Mariotti A. The segmental ridge-split procedure. Journal of Periodontology. 2003, Vol. 74, pp. $757-770$.
8. Robiony M, Polini F, Costa F, Vercellotti T and Politi M. Piezoelectric bone cutting in multipiece maxillary osteotomies. J Oral MaxillofacSurg. 2004, Vol. 62, pp. 759-761.

9. Vercellotti T. Piezoelectric surgery in implantology: A case report-A new piezoelectric ridge expansion technique. Int J Periodontics Restorative Dent. 2000, Vol. 20, pp. 358-365.

10. Marx RE, Carlsson ER, Echstaedt RM, Schimmele SR, Strauss JE and Georgeff KR. Platelet rich plasma growth factor for enhancement of bone graft. Oral Surgery Oral Medicine Oral Pathology Radiology and Endodontics. 1998, Vol. 85, pp. 638-645.

11. Chiapasco M, Abati S, Romeo E and Vogel G . Clinical outcome of autogenous bone blocks or guided bone regeneration with e PTFE membranes for the reconstruction of narrow edentulous ridges. Clinical Oral Implants Research. 1999, Vol. 10, pp. 278-288.

12. Fiorellini, JP and Nevins ML . Localized ridge augmentation/preservation. A systematic review. Annals of Periodontology. 2003, Vol. 8, pp. 321-327.

13. Bogaerde LV, Pedretti G, Sennerby L and Meredith N. Immediate/Early Function of Neoss Implants Placed in Maxillas and Posterior Mandibles: An 18-Month Prospective Case Series Study. Clinical Implant Dentistry and Related Research ISSN 1523-0899. 2010, Vol. 12,pp. 83-94.

14. Zipfel GJ, Guiot BH and Fessler RG . Bone grafting. Neurosurg Focus. 2003, Vol. 14(2), p. e8.

15. Boyan BD, Ranly DM and Schwartz Z . Use of growth factors to modify osteoinductivity of demineralized bone allografts: lessons for tissue engineering of bone. Dent Clin North Am. 2006, Vol. 50(2), pp. 217-28.

16. Buser D, Martin W, Belser U. Optimizing esthetics for implant restorations in the anterior maxilla: Anatomic and surgical considerations. Int J Oral Maxillofac Implants . 2004, Vol. 19, pp. 43-61.

17. Hjørting-Hansen E. Bone grafting to the jaws with special reference to reconstructive preprosthetic surgery. A historical review [in German]. Mund Kiefer Gesichtschir . 2002, Vol. 6, pp. 6-14.

18. Yu B, Long N, Moussy Y and Moussy F . A long-term flexible minimally-invasive implantable glucose biosensor based on an epoxy-enhanced polyurethane membrane. BiosensBioelectron . 2006, Vol. 21(12), pp. 2275-2282.

19. Mahmoudi M, Sant S, Wang B, Laurent S and Sen T. Superparamagnetic iron oxide nanoparticles (SPIONs): 
development, surface modification and applications in chemotherapy. Adv Drug Deliv Rev. . 2011, Vols. 63(1-2), pp. 24-46.

20. Nasir A. Nanodermatology: A Bright Glimpse Just Beyond the Horizon- Part I. Available at: http://www. skintherapyletter.com/2010/15.8/1.html. Accessed March. 2014, Vol. 26.

21. Vercellotti T and Nevins M. Piezoelectric surgery for sinus bone grafting. In Jensen o (ed). The sinus bone graft, ed 2. Chicago: Quintessence . 2006 ,pp. 273-279.

22. Oikarinen KS, Sandor GK, Kainulainen VT and SalonenKemppi M . Augmentation of the narrow traumatized anterior alveolar ridge to facilitate dental implant placement. Dental Traumatology. 2003, Vol. 19, pp. 19-29.

23. Basa S, Varol A and Turker N. Alternative bone expansion technique forimmediate placement of implants in the edentulous posterior mandibular ridge: a clinical report. Int J Oral MaxillofacImplants. 2004, Vol. 19, pp. 554-558.

24. Torella F, Pitarch J, Cabanes G and Anitua E . Ultrasonic ostectomy for the surgical approach of the maxillary sinus: a technical note. International Journal of Oral \& Maxillofacial Implants. 1998, Vol. 13, pp. 697-700.

25. Blus C and Szmukler-Moncler S . The splitcrest procedure with ultra-sonic bone surgery. Results of a 3 year expe- rience with 172 treated sites. Clinical Oral Implants Research. 2004, Vol. 14, pp. xxxvi-xxxvii.

26. Khoury F, Happe A and Hoppe A . Soft tissue management in oral implantology: a review of surgical techniques for shaping an esthetic and functional peri-implant soft tissue structure. Quintessence International. 2000, Vol. 31, pp. 483-499.

27. Sohn DS. Piezoelectric ridge splitting. Dent Success 2003, Vol. 11, pp. 1323- 1328

28. 28. Abd El-Fattah H, Helmy Y, El-Kholy B and Marie M In vivo animal histomorphometric study for evaluating biocompatibility and osteointegration of nano-hydroxyapatite as biomaterials in tissue engineering. J. Egypt Natl. Canc. Instit. 2010, Vol. 22 , pp. 241-250.

29. Jiang JL, Li YF, Fang TL, Zhou J, Li XL, Wang YC and Dong, J . Vancomycin-loaded nano-hydroxyapatite pellets to treat MRSA-induced chronic osteomyelitis with bone defect in rabbits. Inflamm. Res. 2012, Vol. 61, pp. 207-215.

30. Nandi SK, Kundu B, Ghosh SK, De DK and Basu D . Efficacy of nano-hydroxyapatite prepared by an aqueous solution combustion technique in healing bone defects of goat. J. Vet. Sci. . 2008, Vol. 9, pp. 183-191. 
